\title{
Information technology in the study of the quality of concrete work
}

\author{
Sergey Stradanchenko, ${ }^{1, *}$ Stanislav Maslennikov ${ }^{1}, \quad$ Vladimir Dmitrienko ${ }^{1}$, and \\ Irina Kokunko ${ }^{1}$ \\ ${ }^{1}$ Don State Technical University, Institute of service and business (branch) of Don State Technical \\ University, 147 Shevchenko st., 346500 Shakhty, Russia
}

\begin{abstract}
The article presents the results of using information technologies in the study of changes of concrete characteristics at different hardening conditions. The use of the developed temperature measurement complexes made it possible to control the conditions of hardening of monolithic concrete structures directly under production conditions. The results by means of using regression analysis are obtained, regression models of the dependence of the compressive strength of concrete on time and hardening temperature are determined. A significant decrease in compressive strength and resistance to air penetration of concrete samples during their storage under conditions of significant temperature fluctuations has been established.
\end{abstract}

\section{Introduction}

The development of new materials, the introduction of automated design systems and methods of work organization, make it possible to improve construction technology, but builders still have many problems. Since a great majority of construction sites are designed for a long people's life in them, and the service life cycle is to be lasted for decades, they have increased requirements for durability, reliability and safety [1-3]. Even higher requirements are imposed on the objects of underground construction. Despite significant progress, modern tunneling technologies have not had completely safe methods of construction, methods and means of predicting possible accidents yet due to numerous and diverse factors. According to practice, the most common accidents in both built and operated tunnels are associated with rock collapse, lining failure and excavations flooding. Destruction and excessive deformation of the lining cause violations of the adjacent soil mass, which can lead to displacements and deformations of the earth surface, damage of buildings, roads and communications, injuries and death of people, breakdowns of tunnel boring equipment. Therefore, the reliability of lining tunnels is essential.

\footnotetext{
* Corresponding author: vadmitrienko@rambler.ru
} 


\section{Influence of hardening conditions on the reliability of concrete structures}

The vast majority of tunnel excavations are made by means of using shields to mechanize almost all tunneling processes. However, constructing metro stations and auxiliary facilities of small length, due to the peculiarities of objects, the proportion of structures erected from monolithic concrete and reinforced concrete increases. Despite the advantages of monolithic concreting technology and numerous studies in this area, there are a lot of problems for builders. Due to large volumes and stressful construction schedules, construction is carried out a year-round. The intervals for the start of loading of monolithic concrete structures are reduced to a minimum. Researching on the technology of concrete work and the kinetics of concrete strength under normal conditions have been carried out in[5-9], according to which the loading of monolithic structures is possible only after 21-24 days. However, during the cold periods of the year, when doing tunnel work in an open way, this problem becomes particularly acute, since at low temperatures the rate of cement hydration is significantly reduced.

In the studies presented in the papers [10-16], the methods and means of performing concrete work in winter time are given. When certain requirements are met, the strength of concrete during 28 days term at a hardening temperature of $5^{\circ} \mathrm{C}$ does not exceed $80 \%$ of the design conditions, and at a temperature of $1{ }^{\circ} \mathrm{C}$ is less than $70 \%$. In this case, for full capacity of loading of concrete structures, it is impossible to ensure adherence to schedules with building codes and regulations requirements [2].

At the same time, under high temperatures with rapid dehydration conditions, thermal expansion of components, shrinkage of concrete and other physical factors affecting loose concrete the destructive phenomena may appear that drastically reduce its final strength by almost a third [6].

High ambient temperature causes a sharp slowdown or even termination of cement hydration, rapid dehydration of concrete due to intensive evaporation of water and the formation of capillaries in its body directed towards the evaporating surface, which impairs the pore structure of concrete and reduces its strength characteristics. Of particular danger is the early surface shrinkage, accompanied by cracking of the surface, corrosion of reinforcement, loosening of the concrete structure due to expansion-contraction of water that has fallen into it [6].

Analyzing the experience accumulated and conducted research in the field of production and quality control of concrete work, as well as the experience of winter concreting of construction organizations in our region, it can be noted that despite the large amount of information and a detailed description of methods of concrete care at low temperatures, there are a lot of abnormal situations [8]. This requires research to identify the causes that reduce the reliability of monolithic concrete structures.

As a result of researching various methods of heating concrete and hardening accelerators, the main factors (average monthly and minimum ambient air temperature; temperature of the concrete mixture being laid and its survivability; thermal resistance of the formwork and its area) were determined, reducing the reliability of monolithic structures [6]. These factors significantly influenced the rate of structure formation and, accordingly, required constant adjustment of the dosage of modifiers. In addition, on sunny days, even at low temperatures, one-sided heating of the formwork and the development of cracks occur. The geometrical parameters of structures are equally important for cracking and bearing capacity [19]. 


\section{Problems of monitoring of the concrete hardening}

Studies conducted by employees of the department of "Construction and Technosphere Safety" at several sites in Rostov region showed that in winter period concrete gains design strength in three to four months. The required strength of concrete necessary for the installation of structures (60\% of the design) in some cases was gained only after 60-70 days, but during this period the metal frame, roof and even fencing had been already mounted. Since the intensification of construction processes is closely connected with safety, it is necessary to control the time-varying characteristics of concrete. In this regard, one of the most significant tasks is the need to monitor and predict the properties of concrete at different temperatures of hardening [9].

To ensure the proper quality of concrete work, under abnormal conditions, it is possible to do only by operational control of the concrete strength. Despite the wide range of nondestructive testing devices of building materials, to obtain test results with a high degree of reliability under abnormal hardening conditions and at arbitrary hardening periods is very problematic due to the lack of strength dependencies in devices for various temperatures and hydration periods [11].

The use of graphs for gaining strength of modified concrete presented by manufacturers of additives is also impossible, since the tests were performed on samples using high-quality ingredients. Low quality fillers are often used at construction sites. In this case, the development of dependencies for predicting and controlling the concrete characteristics of various compositions and strength classes becomes very important.

\section{Research methods and materials}

The solution of this task is devoted to a large amount of laboratory and full-scale studies of the kinetics of structure formation of modified compositions, carried out by the staff of the Department "Construction and Technosphere Safety" of the Institute of service and business (branch) of Don state technical university. At the same time, special attention was paid to the modeling of conditions close to actual production ones. Laboratory tests were carried out in heat chambers, which allow maintaining the temperature of the samples with an accuracy of $0.1^{\circ} \mathrm{C}$. The registration of the current temperature values in the samples was carried out by a specially developed measuring complex consisting of a personal computer and 8 sensors, allowing recording the temperature for a long time at the construction sites, which ensured the collection, storage and visualization of measurement results. This made it possible to obtain a large amount of data of field observations used by a method for predicting the strength development of concrete at various temperatures.

In the measuring complex, the 1-Wire protocol is used, which has the ability to combine up to 256 devices with a maximum bus length of up to $300 \mathrm{~m}$, while the network can operate even in poor contact conditions. DS1820 microcircuits with a 1-Wire interface were selected as temperature sensors, which allow taking temperature measurements in the range of $-10^{\circ}$ $\mathrm{C}$ to $+85^{\circ} \mathrm{C}$ with an accuracy of $\pm 0.1^{\circ} \mathrm{C}$ with appropriate calibration.

When conducting research in the laboratory at the construction sites for the concrete preparation of classes 7,5-25 with workability of P4 Portland cement aggregates which are usually applied by most construction companies. The graph (Fig. 1) shows the dependence of the concrete strength on the hardening time at various temperatures. 


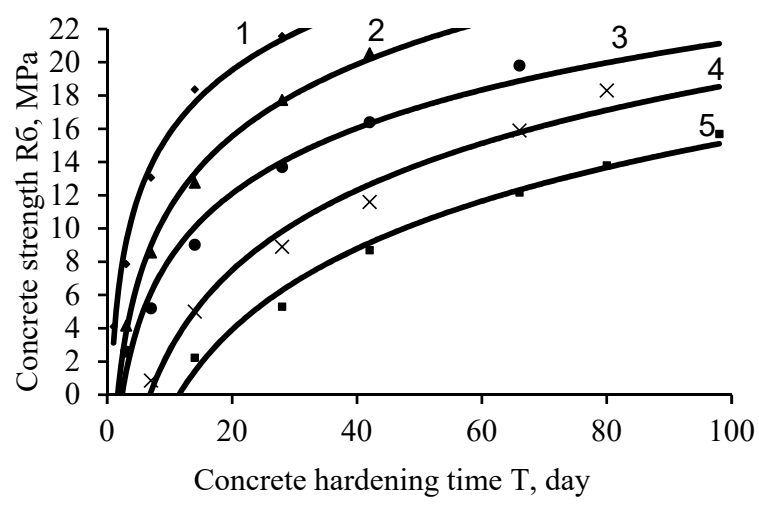

Fig. 1. The kinetics of concrete strength at different temperatures: $1-20^{\circ} \mathrm{C}, 2-15{ }^{\circ} \mathrm{C}, 3-10{ }^{\circ} \mathrm{C}$, $4-5{ }^{\circ} \mathrm{C}, 5-0{ }^{\circ} \mathrm{C}$.

\section{The discussion of the results}

Evaluation of the results of the experiments was carried out directly at construction sites by examining the strength of building structures according to GOST 22690 using the POS-50 MG4-o device by the tear-off method and the IPS-MG4.01 building materials strength meter using the shock pulse method.

The temperature was monitored by the above pointed complex, and monitored by an electronic probe thermometer TTZ-MG 4. The observations were carried out simultaneously on several structures, and the processing results which were hard during periods with slight fluctuations in air temperature.

Comparing the experimental data obtained, we can conclude that the regression equations describing the results obtained under laboratory conditions have satisfactory convergence with production data. Existing discrepancies during long periods of hardening are due to an increase in the temperature of structures during sunny days.

Performed simultaneously with the laboratory, studies of the strength of control samples of concrete structures by means of using non-destructive methods directly at construction sites allowed correcting reference dependencies for IPS MG4 + and POS - 50MG-o devices, thus increasing the accuracy of measurements.

Based on the results of processing the obtained experimental data by using the Statistica software module, multiple regression equations were obtained that allow predicting the required strength of concrete $\mathrm{R}_{\mathrm{b}}$ at different hardening temperatures (Fig. 2). 


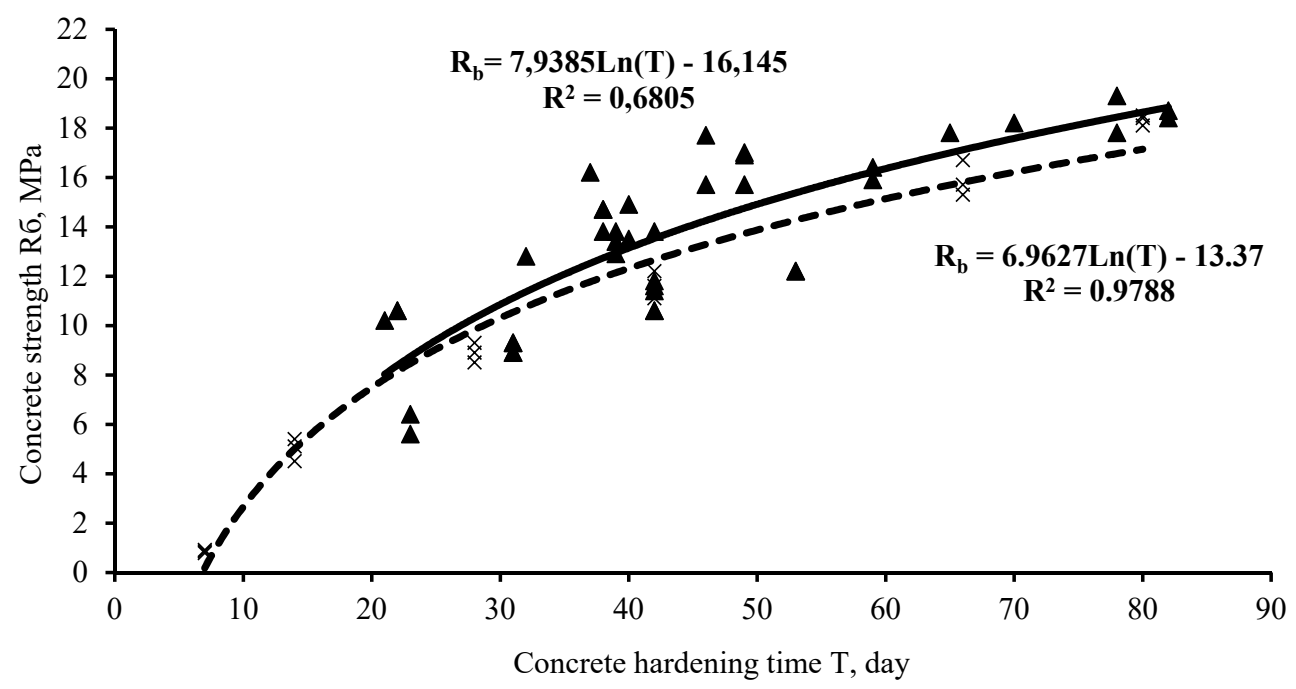

Fig. 2. The dependence of the concrete strength on the hardening time at $5{ }^{\circ} \mathrm{C}$.

$\begin{array}{ll}- & \text { - trend line of production research; }\end{array}$

As modifiers were used in accordance to the request of construction organizations, a number of additives of domestic manufacturers were investigated; this provided maximum efficiency at the lowest cost in compositions with fillers of low quality.

The recommendations developed on the basis of the conducted research allowed construction organizations to carry out early loading of structures at monolithic foundations at four sites in the winter period without their damage.

An equally important factor determining the reliability and durability of monolithic structures is the water resistance of concrete. Given the specificity of operation, this characteristic is especially important for underground structures.

To assess the external effects on the properties of concrete, studies of concrete samples stored in normal conditions and in an open area have been carried out. To control the temperature, a kit based on the ESP32Lit controller has been manufactured. The built-in memory with the appropriate frequency of measurements and a small number of sensors DS18B20, allowed the device to work in autonomous mode for almost a month. The results were read on the smartphone via the local Wi-Fi wireless network without direct contact with the device, which is especially important in terms of construction. Visualization of the results made it possible to obtain thermo grams (Fig. 3) to assess the influence of the conditions of hardening of concrete on strength and water resistance. 


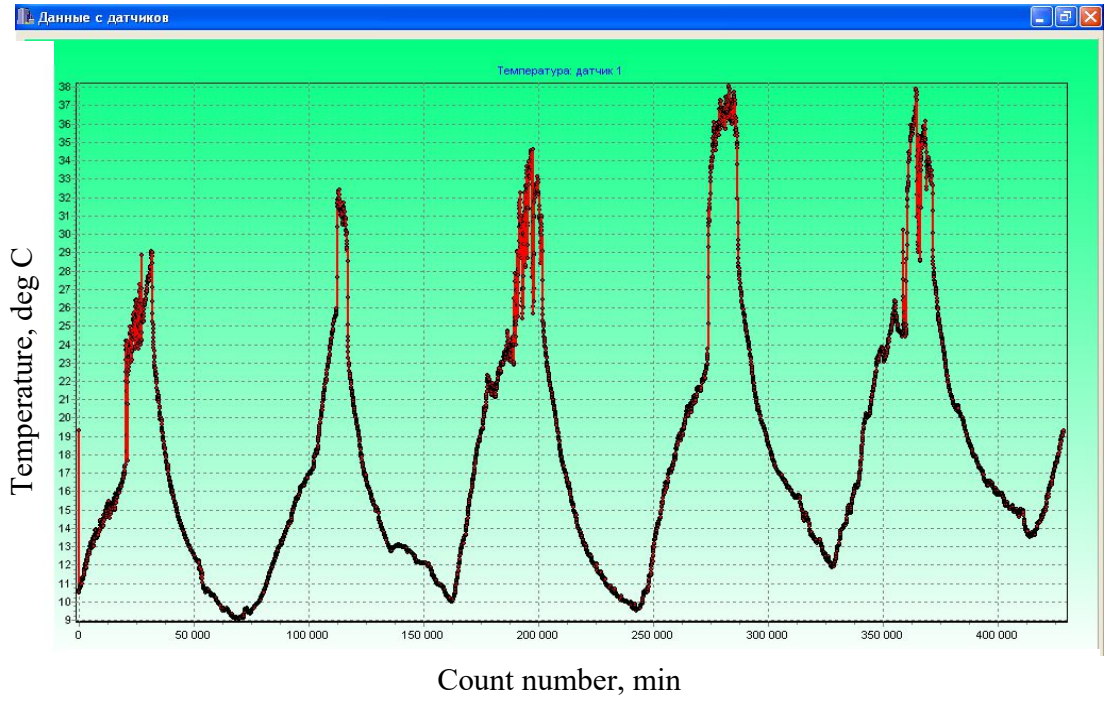

Fig. 3. Fragment of the thermo gram of the surface of the concrete sample.

Analysis of the thermo grams shows that daily fluctuations in temperatures of $30^{\circ} \mathrm{C}$ are almost a constant mode of hardening of concrete structures during sunny days. Moreover, in January and February, a drop of $18-22^{\circ} \mathrm{C}$ in some days could be accompanied by two transitions through the zero mark, despite the relatively "mild" winter of 2018-2019.

The permeability of concrete was evaluated with the resistance of concrete to the penetration of air in accordance with the requirements of GOST 12730.5-84 "Concretes. Methods for determining water resistance."

The results of testing samples of concrete showed that during storage of samples in natural conditions, the compressive strength decreases by an average of $12 \%$ compared to the reference ones, and the air permeability is by almost four times. This is due to a large number of micro cracks in concrete under the influence of temperature differences.

The developed solutions were handed over to the Municipal management commission "Operation of pumping stations" for consideration at the technical council.

\section{Conclusion}

Studies have shown a significant change in the characteristics of concrete with changing storage conditions, which requires consideration when evaluating the reliability of structures. The use of computer technology allows you to significantly reduce the time spent on research and improve the reliability of measurements.

\section{References}

1. Law No. 384 of 23 December 2009 "Technical regulations on safety of buildings and constructions".

2. SNiP 3.03.01-87. M. TSITP of USSR Gosstroi. (1988)

3. SNiP 2.01.07-85*. M. TSITP of USSR Gosstroi. (1988)

4. SNiP 2.03.01.Is 84*. M. TSITP Gosstroy of the USSR (1988)

5. A. M. Pavlenko, Mining information-analytical Bulletin, 9, 170 (2008) 
6. G. M. Badyina, A.V. Meshchaninova. Technology of building production (Stroiizdat, Leningrad, 1987)

7. G. K. Sokolov, Technology of building production (Academy, Moscow, 2007)

8. B. F. Bielecki, Technology of building production (ASV, Moscow, 2001)

9. A. A. Afanasiev, N.N. Danilov, V. D. Kopylov et al., Technology of construction processes (Higher school, Moscow, 2001)

10. M. N. Sborshikova, V. S. Grebenschikov, The Bulletin of foreign scientific and technical information, 5, 30 (2007)

11. V. A. Evdokimov, World practice of construction of monolithic buildings (Leningrad, 1984)

12. Yu. G. Khayutin, Monolithic concrete. Production technology works (Stroiizdat, Moscow, 1991)

13. S. G. Golovnev, Technology of winter concreting. Optimization of parameters and selection methods (Publishing house of the SUSU, Chelyabinsk, 1999)

14. Temporary instructions for the production of concrete works in winter conditions on the objects Slavogorodskaya, Ministry of construction of heavy industry of the USSR "Glavagentstvo", Chelyabinsk, 1985)

15. S. A. Maslennikov, Mining information-analytical Bulletin, 9, 309 (2010)

16. S. A. Maslennikov, K. N. Miroshnichenko, K. S. Yakovlev, The book of Scientific and technical problems of construction and technosphere safety Mines, 54 (2015)

17. S. Nikonorov, O. Tarasova. Magazine of civil engineering, 4, 17 (2010)

18. I. A. Zanina, A. G. Iliev, Proceeding in Intern. Scientific.-Pract. Conf., Part III, ARKONSALT, 31 (2015)

19. O. V. Chernyshenko, A. V. Estrovertida, M. V. Molev, I. A. Zanina, Concept, 15, 1411 (2016)

20. M. S. Pleshko, A. A. Nasonov, O. V. Pashkova, Mining journal, 3, 33 (2015) 